\title{
Evaluation and follow up of Supported Employment initiatives in Spain from 1995 to 2008
}

\author{
F.B. Jordán de Urríes* and M.A. Verdugo \\ Institute on Community Integration (INICO), University of Salamanca, Salamanca, Spain
}

Revised/Accepted: March 2010

\begin{abstract}
This paper is the last in a series of quantitative studies about Supported Employment in Spain, looking at how the situation has changed since the previous studies. The study is based on an Internet survey of all organizations participating in the national ECA Caja Madrid program. The results show a significant increase in the number of organizations that provide Supported Employment programs, in total 202, delivering services to 23,342 users in Spain. This paper analyses the characteristics of the services provided, the users, the professionals and the funding.
\end{abstract}

Keywords: Supported Employment, disability, quality of life, self-determination, research, financial help/aid

\section{The need for periodic data on SE provision in Europe}

Supported Employment (SE), as the European Union of Supported Employment (EUSE) [4] states, has experienced rapid growth in Europe. EUSE states that there are different national factors affecting Supported Employment in each country, which means that the methodology is applied with variations to meet the particular cases. Among these factors, there is: a) lack knowledge and acceptance of a rights-based approach to disabilities; b) absence of a framework of national Supported Employment policies; c) lack of specific funding to stimulate Supported Employment programs; d) overly rigid welfare systems that discourage people from looking for a job; e) political, social and economic priorities and needs in some countries; f) widespread perception of disability in some countries; g) accessibil-

*Address for correspondence: Francisco de Borja Jordán de Urríes, INICO, University of Salamanca, Avenida de la Merced 109131, 37005 Salamanca, Spain. Tel.: +34 923 294695; Fax: +34 923 294685; E-mail: bjordan@usal.es. ity of the conventional labor market and unemployment rates; h) lack of leadership or national strategies relating to the establishment of Supported Employment.

There is no reliable research-based information on these varying realities across Europe. Usually, there is no information at all or it is unknown because SE research in the various Europe countries has been inadequately disseminated. This deficit is replicated globally too, as there is no research that provides a general, comparative perspective on SE in Europe. It is only recently that qualitative information on the provision of Supported Employment in Europe has become available, from the research carried out by Spjelkavik and Evans [18], which offers interesting insights, although, as the authors recognize, it lacks any systematization that would allow conclusions to be extrapolated with a minimum of guarantees on the different national realities. In particular, several studies of Supported Employment have been carried out in the United Kingdom in the last few years [1-3, 19], and some studies have been carried out in Scotland [5, 15] and Finland [14, 16, 17].

In Spain, however, it can be stated there is periodic monitoring of Supported Employment, through sev- 
eral studies carried out by the Instituto Universitario de Integración en la Comunidad [7, 8, 20, 21, 23], with four studies carried out since 1995, with the objective of quantitatively analyzing the Supported Employment initiatives introduced in Spain. This series of studies is complemented by another, more recent one, carried out at European level [6] in a collaborative study led by the Instituto Universitario de Integración en la Comunidad (INICO) together with the Welsh Centre for Learning Disabilities and the European Union of Supported Employment.

In addition, since 2005, INICO has been managing a National Support Program for the development of Supported Employment, known as ECA Caja Madrid, whose function is to allocate funds to Supported Employment programs according to their measured outcomes. ECA Caja Madrid has been developed by the Obra Social (staff mutual fund) at the Caja Madrid Savings Bank. This program has had a major social impact in Spain and carries out specific research on Supported Employment [22].

The research mentioned above allowed us to gain experience and develop tools to facilitate the collection and analysis of information using the Internet. Because of this, and due to the need for studies that provide information on the European situation, annual studies have been planned in the framework of the aforementioned research program, to provide an overview and monitor of the SE situation which, allied with previous studies, will provide longitudinal analysis of SE's status and development.

This paper presents the results of the latest of these studies, carried out on information relating to December 2008. Some comparative references to the previous articles have been added, in a longitudinal approach, wherever the information available has made this possible.

\section{Approach and objectives}

This study is part of an ongoing investigation trying to maintain an annual study with information on the provision of SE programs and services in Spain. In this framework, the main objective of the present study is to present updated information on the provision of SE programs in Spain, using ECA Caja Madrid sponsored programs as a representative sample. With this sample we have a high probability that participants make up almost all of those organizations providing SE in Spain. Other objectives of this study are to analyze: a) the situation of Supported Employment service providers in relation to the transition from segregated to integrated employment services and Quality Management; $b$ ) the users of those services; c) the professionals involved in their provision; d) funding sources.

To achieve this, and based on experience gained, a new tool and an online system have been created to collect information from the programs. We go on to explain this in the next section.

\section{Tool and procedures}

\subsection{The SED survey}

SED (the Supported Employment Data survey) is the tool used in the study. SED was originally developed for the very first study. Its initial development took into account existing findings from various authors [9-13, 24, 25].

SED has been corrected and enhanced by each of the succeeding studies $[8,20,21,23]$, especially via changes made in the third study. The latest version of the survey was deployed for the European study [6] and thus significant change to the tool was required. This version has also been applied in this study and enhanced with parameters agreed at European level, with some extra fine tuning and changes to the later questions on funding issues to implement these items in our particular context. The adjustments made to SED meant changes in the form and type of data collected, which is why some longitudinal comparisons can be made from 1999 and some others only from 2006.

SED consists of 36 items, divided in 6 sections: 1) identification, with 11 items with information about affiliation to the program; 2) transition/quality, with 8 items with information about SE evolution in the organizations and its comparison with other services within the same organization, and about development and evaluation of quality; 3 ) users with 10 items with data about SE services users' profiles and their jobs; 4) professionals with 5 items with information about the profiles of professionals involved in SE services; 5) funding and expenditure has 2 items on SE services' funding sources and expenditure; 6) additional information, for any other information respondents might wish to provide.

Its electronic version is user friendly, offering structured, limited answer options in an attempt to avoid errors, and providing options tailored to the participant's requirements. The survey also has a glossary of concepts to clarify any doubts. 


\subsection{Procedure}

The procedure was structured as follows: 1) agreed definitions of each concept involved in the survey to clarify every question, as far as possible, to avoid differing interpretations. The agreement was made by three experts from different countries with the participation of a member of the European Union of Supported Employment; 2) the study has been developed online, and a password-based application added to allow respondents to complete the survey in one or more sessions; 3 ) definition of the survey sample which, a priori, included every organization on the ECA Caja Madrid program; 4) from the beginning, the compiled data was distributed via e-mail by the program's management team. Several reminders were sent out during the data gathering process; 5) data gathered with the above-mentioned electronic procedure and $100 \%$ of the participants in the program provided responses. Social desirability was not specifically controlled, although most of the data refer to public data that programs use to provide to funders and administrations or to publish in annual reports of their activities so we were not afraid about this problem; 6) information processing and analyzing in a descriptive way using percentages; 7) preparation of the research report.

\section{Outcomes}

\subsection{Transition/quality}

The first approximation that we can make of Supported Employment relates to how initiatives have evolved over the years. A progressive but slow increase can be observed from the late 80s to the end of 2004 when 93 programs exist in Spain. However, the initiatives began to grow strongly after the year 2005, coincident with the start of ECA Caja Madrid, and initiatives more than double after the program starts, reaching a total of 202 in 2008.

As regards the general services available in the organizations, the vast majority $(89 \%)$ provided specific supported employment services, whilst $11 \%$ provided practical actions without having a specific supported employment service. We also found that SE services co-exist with other services in the organizations, mainly with employment training (41\%), occupational centers (34\%) and special employment centers (30\%). Additionally, there was an analysis of the availability of resources for the next twelve months in the services referred to in the previous question. In the first place, we found that, despite the general availability of SE services, medium-term funding was not guaranteed in all cases, as only $61 \%$ of the organizations stated that they had such funding. The data also revealed that the other services provided by the organization had less funding stability for their provision. Both circumstances highlight the importance of ECA Caja Madrid as a stable source of funding for SE programs in our country. However, the current information reveals trends running counter to those of previous studies. This might be due, on the one hand, to a real and very desirable change or, on the other hand, to unawareness among the SE program professionals who completed the survey of the availability of other resources for other services offered by the organization. As long as we have no certainties about this information, it has to be analyzed with caution.

Focusing on Supported Employment, we analyzed the services portfolio offered by the programs. We found a very high percentage, between $88 \%$ and $97 \%$, provide the 'traditional' intermediation services: personal evaluation, personal plan development, and job search and job evaluation. A high percentage of programs offered pre-employment training (77\%), whilst the percentage of those who offered on-the-job training was noticeably lower $(69 \%)$. The percentage of programs offering support outside the workplace was also significant $(82 \%)$, even though the percentages of support offered in the workplace from 1 to 3 months (62\%), from 1 to 12 months $(54 \%)$ or beyond $(67 \%)$ were noticeably lower. Support provided for other activities, such as leisure (57\%) and free time (61\%) was interesting. This information is key to a multidimensional approach to planning improved quality of life. In this issue, we must consider the variety of people using ECA Caja Madrid services via the participating organizations, their different support needs and differences in the practices of persons with disabilities as a group and the socially excluded as a group (in Spain, as will be mentioned in next point, supported employment services are provided to both people with disabilities and people who are "socially excluded" as: Ethnic minorities, Drug abuse, Immigrants \& refugees, Homeless, Ex offenders, HIV, and others).

As for evaluation, $76.33 \%$ of the organizations stated that they carry this out. In this group, $55.88 \%$ used internal procedures. The remaining group $(44.12 \%)$ stated that they used external and independent methods, of which $38.82 \%$ were using both methods, and 5.29\% only employed the external independent method. We 
consider that these evaluations need to be done periodically, and that external evaluation, besides guaranteeing objectivity can provide improvement goals that internal methods would not.

In-depth evaluation of the different evaluation methods used revealed low percentages, fluctuating between $5 \%$ and $31 \%$, depending on the methodology, which was highly variable. ISO methodology seems to be the most used, in $31 \%$ of the cases, followed by focus or work group techniques in $21 \%$ of the cases, and documentation of good practices. In this respect, it is important to complement the techniques applied, and in every case, to use methods that meet tested international standards that provide agreed references.

Another of the issues focuses on program participation in research, as only $17.87 \%$ of them stated that they did so. Besides, among those who stated that they did participate in research, only $14.49 \%$ stated that they collaborated with universities or similar institutions. Specifically, of this group, $40.98 \%$ of them collaborated with universities, $31.15 \%$ with government bodies and $11.48 \%$ with private research institutions, while the remaining $16.39 \%$ stated that they collaborated with other kinds of institutions. The major shortcoming revealed by the information on this issue is significant, since it is crucial to the progress of the initiatives, since it is closely related to evaluation. A culture of cooperation with research bodies must, then, be encouraged, as it means benefits to the programs and to the users. To this must be added the importance of creating synergies between those entities with real research skills and capacities, in this case the universities and research institutions, which can provide the necessary criterion and rigor. Research should not be initiated merely by the research bodies; instead the programs and organizations should seek to collaborate to ensure that their practical needs and establish mutual collaborative links.

\subsection{Users}

The distribution of the overall population of the users of ECA Caja Madrid supported employment services can be seen in Tables 1 and 2, which includes every person who had ever obtained a job, whether persons with disabilities or persons suffering social exclusion. Regarding the first group, the largest subgroup consisted of persons with intellectual disabilities (40\%), followed by persons with hearing disabilities $(30 \%)$, whilst third place was occupied by persons with disabilities affecting mobility (14\%). We found in this environment the extension of the Supported Employment model to the major disability types. For those suffering social exclusion, we found ethnic minorities (as gypsies, Africans, Asians, and others) formed the major group (34\%), followed by immigrants and refugees (19\%) and drug addicts and alcoholics (11\%). We also see the solid establishment of the Supported Employment model in the work being carried out with these populations. Analysis of the comparable data from 1996 to 2008 revealed a progressive percentage decrease in persons with intellectual disabilities, from $72 \%$ to $40 \%$.

In general terms, Tables 1 and 2 shows 23,342 people had obtained a job thanks to supported employment programs. This figure is composed of 14,159 persons with disabilities and 9182 persons suffering from social exclusion. We also found that 7547 persons are currently working thanks to supported employment programs, composed of 5090 persons with disabilities and 2457 persons suffering from social exclusion. Comparison of these figures allowed us to

Table 1

Persons with disabilities by employment situation, maintenance and number of hours worked per week

\begin{tabular}{|c|c|c|c|c|c|c|c|c|}
\hline \multirow[b]{2}{*}{ Intellectual disability } & \multicolumn{2}{|c|}{$\begin{array}{c}\text { Placed in } \\
\text { employment }\end{array}$} & \multicolumn{2}{|c|}{$\begin{array}{l}\text { Currently } \\
\text { working }\end{array}$} & \multirow{2}{*}{$\begin{array}{c}\begin{array}{c}\% \text { of Job } \\
\text { tenure }\end{array} \\
40.64\end{array}$} & \multirow{2}{*}{$\begin{array}{c}\% \text { of }<12 \\
\text { hours/week }\end{array}$} & \multirow{2}{*}{$\begin{array}{c}\% \text { of } 12-24 \\
\text { hours/week }\end{array}$} & \multirow{2}{*}{$\begin{array}{c}\begin{array}{c}\% \text { of }>24 \\
\text { hours/week }\end{array} \\
65\end{array}$} \\
\hline & 5.655 & $39.94 \%$ & 2.298 & $45.15 \%$ & & & & \\
\hline Autism \& GDD & 99 & $0.7 \%$ & 20 & $0.39 \%$ & 20.20 & 20 & 40 & 40 \\
\hline Physical disability (mobility) & 1.911 & $13.5 \%$ & 558 & $10.96 \%$ & 29.20 & 4 & 25 & 71 \\
\hline Physical disability (organic) & 706 & $4.99 \%$ & 296 & $5.82 \%$ & 41.93 & 2 & 10 & 87 \\
\hline Cerebral palsy & 44 & $0.31 \%$ & 25 & $0.49 \%$ & 56.82 & 8 & 52 & 40 \\
\hline Visual disability & 138 & $0.97 \%$ & 56 & $1.09 \%$ & 40.58 & 2 & 21 & 77 \\
\hline Auditory and communication disability & 4.281 & $30.24 \%$ & 1.380 & $27.12 \%$ & 32.24 & 3 & 4 & 93 \\
\hline Psychiatric disabilities & 1.110 & $7.84 \%$ & 352 & $6.92 \%$ & 31.71 & 5 & 28 & 67 \\
\hline Brain injury & 29 & $0.2 \%$ & 18 & $0.35 \%$ & 62.07 & 0 & 33 & 67 \\
\hline Others & 186 & $1.31 \%$ & 87 & $1.70 \%$ & 46.77 & 1 & 13 & 86 \\
\hline Total & 14.159 & $100 \%$ & 5.090 & $100 \%$ & 35.95 & 4 & 21 & 75 \\
\hline
\end{tabular}


Table 2

Persons suffering from social exclusion, by employment situation, maintenance and number of hours worked per week

\begin{tabular}{|c|c|c|c|c|c|c|c|c|}
\hline \multirow[b]{2}{*}{ Ethnic minorities } & \multicolumn{2}{|c|}{$\begin{array}{c}\text { Placed in } \\
\text { employment }\end{array}$} & \multicolumn{2}{|c|}{$\begin{array}{l}\text { Currently } \\
\text { working }\end{array}$} & \multirow{2}{*}{$\begin{array}{c}\% \text { of Job } \\
\text { tenure }\end{array}$} & \multirow{2}{*}{$\begin{array}{c}\begin{array}{c}\% \text { of }<12 \\
\text { hours/week }\end{array} \\
9\end{array}$} & \multirow{2}{*}{$\begin{array}{c}\begin{array}{c}\% \text { of } 12-24 \\
\text { hours/week }\end{array} \\
38\end{array}$} & \multirow{2}{*}{$\begin{array}{c}\begin{array}{c}\% \text { of }>24 \\
\text { hours/week }\end{array} \\
54\end{array}$} \\
\hline & 3.141 & $34.21 \%$ & 415 & $16.89 \%$ & & & & \\
\hline Drug abuse & 1.005 & $10.95 \%$ & 309 & $12.58 \%$ & 30.75 & 2 & 12 & 85 \\
\hline Immigrants \& refugees & 1.744 & $18.99 \%$ & 559 & $22.75 \%$ & 32.05 & 2 & 10 & 89 \\
\hline Homeless & 171 & $1.86 \%$ & 100 & $4.07 \%$ & 58.48 & 8 & 15 & 77 \\
\hline Ex offenders & 729 & $7.94 \%$ & 154 & $6.27 \%$ & 21.12 & 0 & 1 & 99 \\
\hline HIV & 225 & $2.45 \%$ & 67 & $2.73 \%$ & 29.78 & 3 & 6 & 91 \\
\hline Others & 2.167 & $23.60 \%$ & 853 & $34.72 \%$ & 39.36 & 1 & 9 & 90 \\
\hline Total & 9.182 & $100 \%$ & 2.457 & $100 \%$ & 26.76 & 3 & 14 & 83 \\
\hline
\end{tabular}

calculate a maintenance percentage, as a proportion of those people currently working against the number of persons who have ever had supported employment. Further, the hand, maintenance percentage across all ECA Caja Madrid supported employment programs was seen to be $32.33 \%$. This figure shows the difficulty of maintaining the population that uses this type of program in the labor market. In particular, the maintenance percentage of persons with disabilities rises to $35.95 \%$, led by brain damage $(62 \%)$, cerebral palsy $(57 \%)$, and the lowest being autistic disorders (20\%) and physical disabilities affecting mobility (29\%). Regarding people affected by social exclusion, the maintenance percentage was $26.76 \%$, led by transients and homeless persons $(58.48 \%)$ at the top, followed by immigrants and refugees $(32.05 \%)$ and ethnic minorities (13.21\%) and ex-prisoners (21.12\%) at the bottom. These figures must be weighted in the two general groups by the number of total users in each subgroup.

Information was also collected on the weekly number of hours worked by supported employment users. Tables 1 and 2 show that, for persons with disabilities, the most usual average number of hours worked per week was over 24 hours, in $75 \%$ of the cases, though there were major variations according to type of disability, since in some of them, such as hearing disabilities, the number of hours worked per week exceeded 24 hours in $93 \%$ of the cases, while in some others, like cerebral palsy or autistic disorders, number of hours worked per weeks over 24 hours only occured in $40 \%$ of cases, with a predominance of number of hours worked per weeks between 12 and 24 hours, followed by $20 \%$ of persons with autistic disorders with a number of hours worked per week of 12 hours or less. This information reveals special problems in providing standard working hours in some populations, with a consequent further reduction in job opportunities. The same analysis was made of the population affected by social exclusion which, in general terms, had a 24 hours or longer number of hours worked per week in $83 \%$ of the users. Variations in this group were lower though; ex-prisoners had an average number of hours worked per week of 24 hours or more in $99 \%$ of cases and the biggest challenge related to ethnic minorities, with only $54 \%$ working more than 24 hours a week and $38 \%$ with a number of hours worked per week of between 12 and 24 hours.

As regards the distribution of supported employment users by age and gender, we first found $56.51 \%$ of men, compared to $43.49 \%$ of women. In both groups, the predominant age range was between 26 and 45 years, with $35.61 \%$ and $28.02 \%$ respectively. This range was followed by the range 16-25 years with $11.4 \%$ and $9.13 \%$ respectively. From another angle, $63.63 \%$ of cases were in the main 26-45 years range, followed by the $16-25$ range $(20.52 \%), 46-65(15.67 \%)$ and, finally there was the group of over-65s $(0.18 \%)$. In every age range, except the last one, men leaded the figures, with percentages of $35.61 \%, 11.4 \%$ and $9.44 \%$ respectively. In general terms, we noticed gender distribution by age was very similar to the one found in the preliminary information from the EDAD survey, where men slightly leaded the group until the age of 55. We can therefore observe that no specific gender discrimination was found among those Supported Employment users currently working. However, as regards age, the EDAD survey showed progressive increases in the number of people in each range. In our study, the results were different, showing users were mainly in the $26-45$ range. We can therefore state that there was under-representation of people over 45 among the users of supported employment currently working.

As regards changes between 1996 and 2008 affecting, respectively, the gender and age of supported employment, we found differences favoring men had progressively decreased from $64 \%$ to $57 \%$. As for age, 


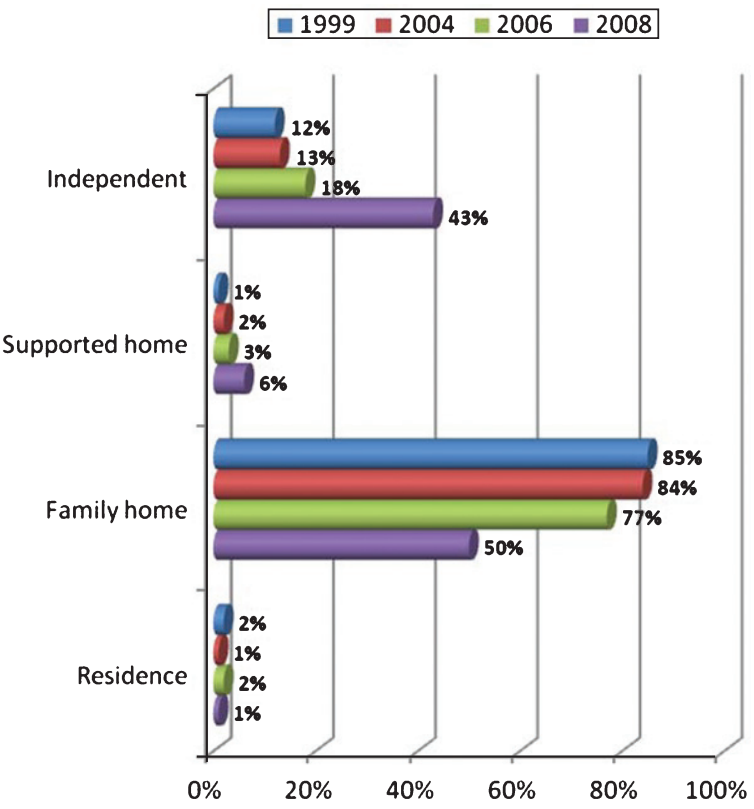

Fig. 1. Percentage of persons on SE programs by type of residence.

we saw the 26 to 45 age range consolidated as the leading group and job access for younger people (between 16 and 25 years) had fallen from $31 \%$ to $20 \%$.

Education level is one of the key issues in finding a job. For all users of ECA Caja Madrid programs in 2008 $(51 \%)$ had completed mainstreaming education, whilst $7 \%$ had attended special education. Beyond this level, $18 \%$ had participated in vocational training and even lower percentages (10\% and 5\%) had completed postmainstreaming and higher education. Over time, we found that the percentage of users who had completed mainstreaming education increased between 2004 and 2008 , from $43 \%$ to $51 \%$, and similarly for those who completed vocational training, increasing from $11 \%$ to $18 \%$.

As regards the residences of the users of supported employment (Fig. 1), half of them (50\%) lived in the family home, while $43 \%$ lived alone and $6 \%$ lived in a supported home. Longitudinal analysis revealed a significant increase in independent homes and decreases of those living in the family home, which was probably due to increases in the number of persons suffering from social exclusion, who have emerged strongly in the last two years.

The vast majority of employment contracts obtained in the twelve months of 2008 are temporary contracts (77\%), as shown in Fig. 2. This temporary rate equates to three times the rate recorded in the Spanish Labor

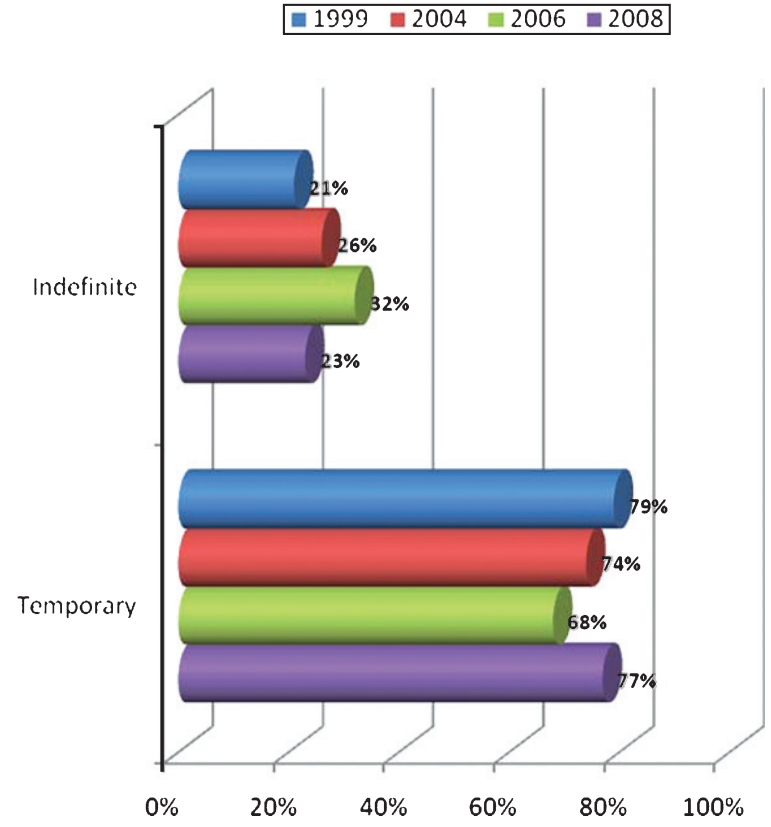

Fig. 2. Percentage of persons in SE programs by type of contract.

Force Survey (1st quarter 2009) ${ }^{1}$ for the general population, which showed a rate of $25.41 \%$ for temporary employment. Over time, we clearly see that, after a solid increase in stability, the economic crisis has created a new increase in temporary rates.

Across the user population for supported employment programs, most received less than 5 support hours per week, whilst $19.8 \%$ received between 5 and 10 support hours a week and the remaining $14.85 \%$ had more than 10 support hours a week. It is probable that a large number of those who got less than 5 support hours a week were already in the maintenance phase of their employment.

One surprising piece of data, compared with recent data obtained by research in Europe (Jordán de Urríes, Beyer and Verdugo, 2008), was found in the average hourly earnings of supported employment users. This research showed $€ 5.33$ an hour as the average earnings for workers in Spain and $€ 5.47$ an hour was earned in all the countries participating, whilst the United Kingdom, had highest average earnings of $€ 7.57$ an hour. It was surprising to find average earnings in our study of $€ 11.4$ per hour, a figure almost four times greater than the extrapolation of the national minimum wage of $€ 3.41$ per hour. A possible explanation for this difference is that organizations are not familiar with

\footnotetext{
${ }^{1}$ In Statistics National Institute press release.
} 
hourly earnings information which, at the same time, is the only objective comparable information, so the figures provided might be mistaken or confused. It is necessary then for clearer, more objective procedures to be defined to obtain this information in future research.

\subsection{The professionals}

Training provided by organizations to the professionals is a key element for their professional development, their retraining and job motivation, and development of innovative practices to achieve improvements. Sixty five percent of ECA Caja Madrid participant organizations gave specialist training on disability to their professionals. That percentage was ever higher in relation to specialist training on supported employment, as $76.33 \%$ of the organizations participating in ECA Caja Madrid stated that they provide it. Although we consider these to be high percentages, we also believe it is necessary to develop those practices in $100 \%$ of the organizations providing services for persons with disabilities and, more specifically, in supported employment programs. This need is even more obvious after finding that only $50.24 \%$ of the organizations in our research provided ongoing specialist training and retraining to their professionals. Organizations that make no logical, planned investment in this area risk the quality and continuity of the services they provide, besides making it harder to develop integrated, dynamic professional teams committed to service improvement and quality. We finally found, in comparing the last two studies (2006 and 2008), that the percentage of organizations providing specialist training had increased and even accelerated in relation to training on SE, as the 2006 data showed 59\% for this kind of training, broke down into $41 \%$ for continuous training and $63 \%$ for disability in general.

The staff of supported employment programs participating in ECA Caja Madrid was broken down into job coaches (50\%), job finders (21\%), managers (16\%) and the remaining $13 \%$ were administrative assistants. It is important to highlight that each of these belong to the team that delivers the program, that they are all necessary, and that we should not only consider the job coach. Team development is essential and open funding for the teams is crucial. Longitudinal analysis showed that, between 1999 and 2008, even though there have been some changes in the distribution of the groups, percentages showed significant stability over the last two studies.
Concerning the average hourly earnings of the program professionals, according to their professional profile, information collected casts further doubts over the data from afore-mentioned European study. According to that study, Spanish average wages were $€ 9.75$ per hour for job coaches, $€ 10.99$ per hour for job finders, $€ 9.04$ per hour for administrative staff and $€ 11.41$ per hour for managers. It is, therefore, surprising to find out in this study that for the same job categories average wages were $€ 7.2, € 14.29, € 18.47$ and $€ 25.07$ per hour, respectively. These figures differ excessively between the professional categories and, in some cases, significantly different from those found in previous studies. We believe, once again that there is a need to clarify the procedures that will be used in future to collect this information.

\subsection{Funding}

The final information collected in the survey referred to the sources and amounts of funding. The information in Fig. 3 shows that, compared to the total amount, funding came mostly from regional governments, being $45.5 \%$ of total funds. The second source of funds, in percentage terms, was ECA Caja Madrid, being $10.8 \%$ and the third source was national private sources $(7.56 \%)$ excluding Caja Madrid's Obra Social and La Caixa's Obra Social. It is therefore useful to mention some issues. In the first place, ECA Caja Madrid program's importance as the second source of funds by relative amount of funds (10.83\%). Secondly, there is a scarcity of public funding on a national basis (4.38\%), and regional funding based on the Royal Decree on supported employment $(6.78 \%)$. Thirdly, it is important to note the scarcity of European public funding (5.35\%), which was even exceeded by contributions from local companies $(5.92 \%)$. Finally, mention must be made of private funding which makes up $32.08 \%$ of total funds.

Focusing on national bases for funding, only $14.94 \%$ came from public sources and the rest, $35.87 \%$, was provided by ECA Caja Madrid, $16.31 \%$ points higher than the funds provided by La Caixa (19.56\%), to which we must add $5.04 \%$ to take into account funding offered by other employment programs from Caja Madrid's Obra Social, accounting for $40.91 \%$ of the segment. The rest accounted for $25.04 \%$.

For regional funding, accounting for $54.52 \%$ of the total, funds originating in Royal Decree 870 on employment regulation, signed on 2 July 2007, accounted for only $12.44 \%$ of this segment. Of the remaining funding, 


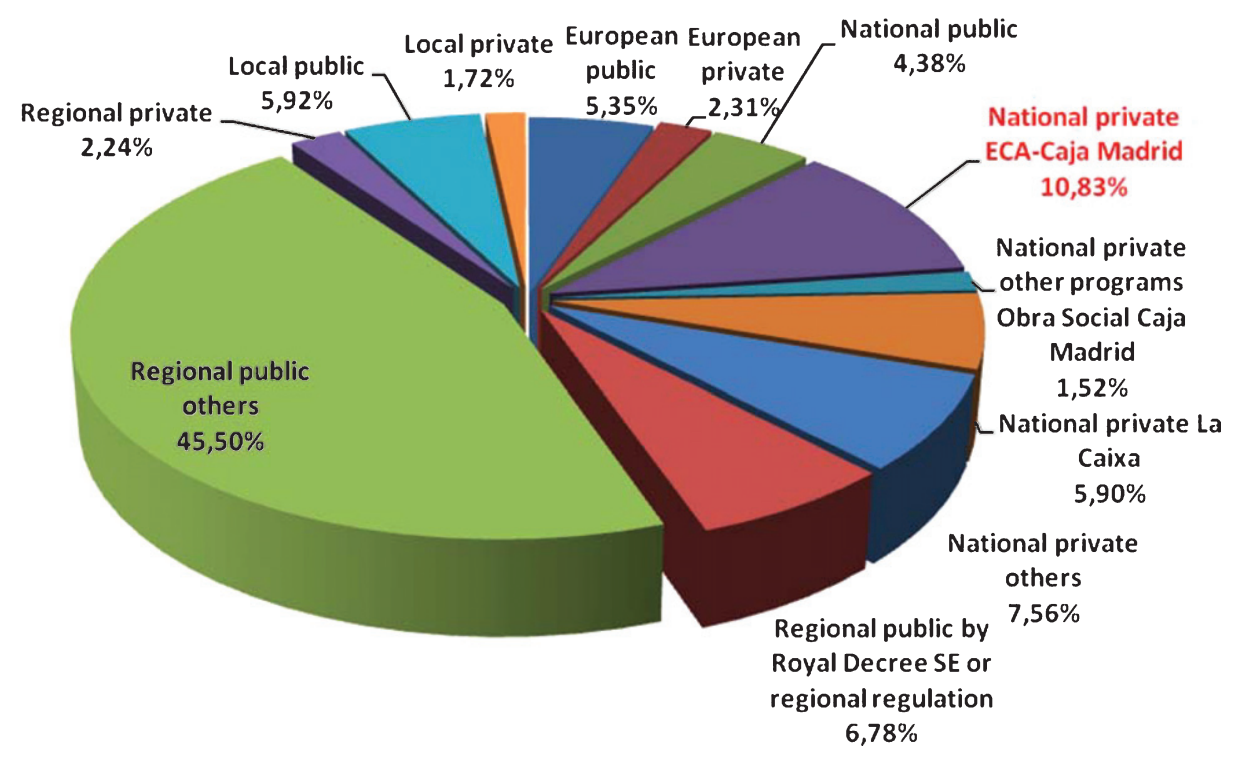

Fig. 3. Global percentage of funding by source.

$4.10 \%$ came from private sources, and most $(83.46 \%)$ came from other kinds of sources.

Finally, and to end the data presentation, Fig. 4 presents percentage changes to funding over time for the four categories mentioned above, and we found a significant decrease in European funds, a clear increase in national funding, and the consolidation and stabilization of regional funding, as the main source of funds.

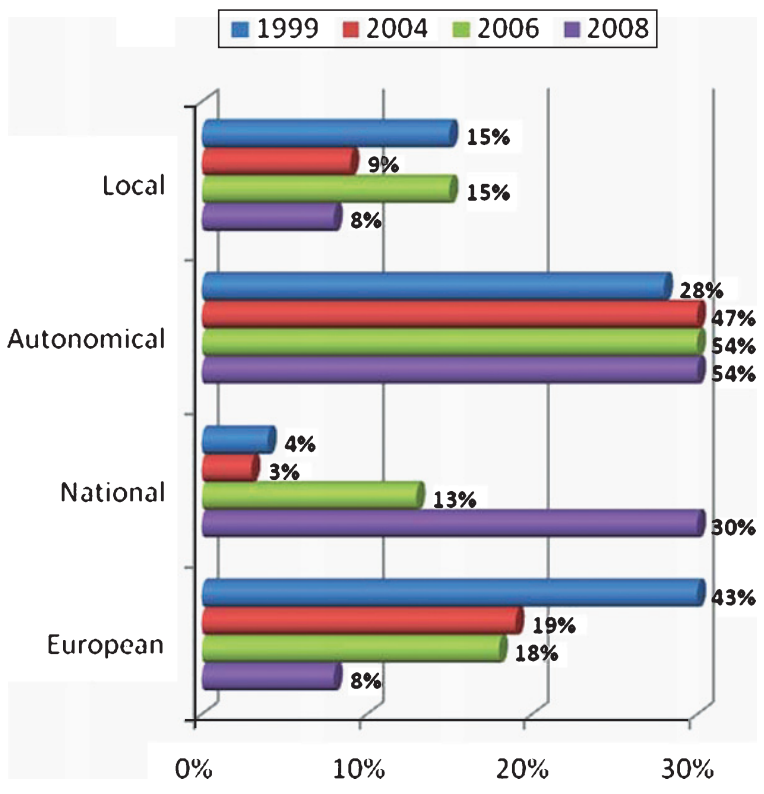

Fig. 4. Percentage of funding by source at regional level.

\section{Conclusions}

Supported employment in Spain has seen slow but continuous growth, with a substantial increase since the establishment of the ECA Caja Madrid program, since which time initiatives have doubled, reaching 202. This information shows the importance of adequate, stable sources of funding in making possible the expansion and consolidation of supported employment services.

Alongside supported employment, a multiplicity of other services coexists in the same organizations. Supported employment shows greater availability of scheduled funding for the next 12 months than other services, although $39 \%$ of organizations lack secure funding. It is essential to foster the transition of organizations to alternative community services, which will require resources to be aligned behind the provision of this type of service.

Supported employment programs offer a range of different services, according to their own nature, which mostly include the most traditional intermediation services (personal evaluation, personal plans, job search and evaluation). However, medium and long-term support has not developed sufficiently (only between 54\% and $67 \%$ of the programs). It is essential not to lose sight of supported employment's original main objective, which is to provide support to persons with the greatest difficulties. This means continuous support structures must be available, capable of meeting any support needs 
that might appear in the medium or long term to threaten employment stability.

Even though the main offers relate to evaluation $(76.33 \%) 55.88 \%$ only provide internal evaluation techniques, and use no external and independent techniques. In addition, evaluation practices are diverse and only a small percentage use standard and widely tested evaluation systems, such as ISO (31\%), while European Union of supported employment standards are used in a very low percentage (5\%). Quality culture must inform service provision. Process quality, backed up by international standards, and the user's quality of life, will improve when we can achieve results centered on the individual.

Only $17.87 \%$ of the organizations participate in research, and in few of those cases is the research carried on with or by specialist institutions (14.49\%). Research and, of course, evaluation, are key elements in providing and enhancing programs and services. Developing solid research in competent institutions with the research skills and resources must be a given for all programs. To do so, researchers and service providers should be aware of mutual needs for collaboration. On their side, the scientific community should enable applied research to acquire data that will affect enhancements and decision-making.

Supported employment programs are widely deployed for the main groups of persons with disabilities, mostly for those with intellectual disabilities (40\%) and hearing disabilities (30\%). Over time, the incidence of persons with intellectual disabilities has diminished due to an increase in the other groups. Likewise, the percentage of persons suffering from social exclusion has grown, especially ethnic minorities (34\%) and immigrants and refugees (19\%). Thus, supported employment methodology is applied to a vast range of populations, hence the need for adequate consideration of tailoring it to people's specific needs, bearing in mind the program' main objective, which is to provide integrated job opportunities to those in greatest need of support.

Of the 23,341 users of Supported Employment programs who have found some form of employment (14,159 persons with disabilities and 9182 persons suffering from social exclusion), currently 7547 are found to be working (5090 persons with disabilities and 2457 suffering from social exclusion). We observe, then, a general percentage of maintenance in jobs of $32.33 \%$ (35.95\% for persons with disabilities and $26.76 \%$ for persons suffering from social exclusion). These quite low percentages reflect the real diffi- culty of supporting users of SE programs in the labor market.

The average number of hours worked per week is more standard amongst users suffering from social exclusion, where $83 \%$ work more than 24 hours per week, whilst, as a population, ethnic minorities have differ most from the standard, with only $54 \%$ of them working more than 24 hours per week. In the segment of persons with a single disability, $75 \%$ of users work more than 24 hours per week, whilst the populations of persons with autism or cerebral palsy have the lowest percentage (40\%) above the 24 hours' threshold. This invites a twin conclusion. On the one hand, there is the advantage of trying to obtain standard employment with working days and average number of hours worked per week similar to those of the population without disability. On the other hand, however, there is a need not to lose sight of the special adaptations for each person that may vary how the working day and the number of hours worked per week are calculated. It should never be forgotten that employment is not an outcome in itself, but aims to develop the whole person and contribute to the enjoyment of a normal adult life. The work is for the person, not the person for the work.

The majority of Supported Employment program users are male $(56.51 \%)$ and the main age range is from 26 to 45 years old $(63.63 \%)$. We find, on the one hand that the gender gap has diminished in the various surveys carried out whilst, compared with the early data from the EDAD survey, carried out in Spain by the Ministry for Health and Social Policy, we find no discrimination on grounds of gender, since the population of working age is distributed in similar proportions. We do, however, find age discrimination, with underrepresentation of the over- $45 \mathrm{~s}$. The programs have a responsibility to avoid, as far as possible, adding discriminatory circumstances in addition to program users' own situation of disability. Gender, age or other individual variables should not present further barriers.

The educational level of the majority is that of mainstreaming education $(51 \%)$, a forgiven which has grown over the successive studies, whilst the family home is the most common residential environment (50\%). This has been falling progressively in the studies carried out in favor of independent living which has increased as a percentage (43\%), probably because of the increased presence of users suffering from social exclusion who have a higher level of independence. The great majority of Supported Employment users $(65.35 \%)$ receive less than 5 hours support per week. The increase in mainstreaming education reflects, we believe, the increase 
in mainstream education for persons with a disability, although only small percentages for higher education alternatives, which should be encouraged. The increased autonomy in the type of residence is welcome, but it should not be forgotten those who are adults for work purposes can also be adults who live independently and this is something that should be fostered.

The majority of contracts of the last 12 month are temporary; three times the temporary rate of the general population. The rising trend to indefinite contracts seen in the previous studies has been clearly reversed in the last study, faithfully reflecting the socioeconomic crisis that characterizes the present situation. This does not negate the need to provide quality employment which encourages stability as, in so doing; it would enable the employee to plan their life in peace and with confidence. The average salary was found to be $€ 11.4$ per hour, well above the minimum wage and higher than in other recent studies. However, because the service providers are unfamiliar with this way of quantifying the hourly salary, this data must be analyzed with caution and how it is obtained must be clearly specified in future studies.

$65.70 \%$ of the organizations provide training to their professionals on disability or on social exclusion, and $76.33 \%$ provide it for Supported Employment, although only $50.22 \%$ of the organizations have planned ongoing training. Increasingly, more organizations are involved in this task. It should not be forgotten that specific initial training and adequate training for professionals are a key factor in the programs' success. However, it is no less important for continuous, periodic updating to encourage the maintenance of service quality and the development of good practices and, further, maintain motivation and provide a periodic breather for the professionals.

The staff on the programs consists mainly of job coaches (50\%), job finders (21\%), managers (16\%) and administrative staff (13\%), with corresponding average hourly wages of $€ 7.21, € 14.29$, $€ 25.07$ and $€ 18.47$. It is necessary to analyze this data with caution and improve its collection procedures for the reasons mentioned above. In any case, there is a need adequately to reward the professionals, who are required, in many cases, to show wide availability, versatility, very varied skills and, always, effectiveness.

The funding for these programs comes mainly from regional public funds $(45.50 \%)$, whilst the funding method in the Royal Decree on Supported Employment still only has a minor role $(6.78 \%)$. ECA Caja Madrid is the second source of funding at a general level $(10.83 \%)$, and the main source in the national funding segment $(35.87 \%)$. We dedicate the final finding of this study to the need to align program targets with the economic resources. If we wish to provide access to normal employment for persons with disabilities, we must have stable, open funding lines that are adequate for the programs that they support. Supported Employment has demonstrated over the years, with results-based evidence, its effectiveness in achieving this target. To do so, it has to receive adequate, dignified funding. The recent standards regulations in Spain have opened up a framework that encourages this provision but it suffers significant shortcomings that must be evaluated and analyzed in depth. The private initiatives via the ECA Caja Madrid program are playing a major role in countering these shortcomings, but they are still insufficient.

\section{References}

[1] S. Beyer, Trends in Supported Employment, Tizard Learning Disabilities Review 6(2) (2001), 36-39.

[2] S. Beyer, L. Goodere and M. Kilsby, The Costs and Benefits of Supported Employment Agencies: Findings from a National Survey, Employment Service Research Series, No. 37, Stationery Office, London, 1996.

[3] S. Beyer, J. Thomas and P. Thornton, The Net Costs and Individual Benefits of the Supported Employment Programme, Report WAE 152, Department of Work and Pensions Research management, Sheffield, 2003.

[4] M. Evans, I. Lopes, C. Katsouda, A. Diepeveen, M. Fleming, M. Haddock, T. Hazzard, S. Schuller, M. Johnova, P. Boxava, S. Martínez, F.B. Jordán de Urríes, B. Eklund, L. Sariola and H. Haltunen, Information Booklet and Quality Standards, European Union of Supported Employment, Belfast, 2005.

[5] S. Hunter and J. Ridley, Supported Employment in Scotland: Some issues from research and implications for development, Tizard Learning Disability Review 12(2) (2006), 3-13.

[6] F.B. Jordán de Urríes, S. Beyer and M.A. Verdugo, Estudio comparativo sobre la situación del Supported Employment en Europa, in: 2nd Premi Investigació i innovació sobre persones amb discapacitat intellectual, Treballs premiats 2008, AMPANS, Manresa, 2008, pp. 115-194.

[7] F.B. Jordán de Urríes, M.A. Verdugo and C. Vicent, Análisis de la evolución del empleo con apoyo en España, Real Patronato sobre Discapacidad, Madrid, 2005.

[8] F.B. Jordán de Urríes and M.A. Verdugo, El Empleo con apoyo en España. Análisis de variables que determinan la obtención y mejora de resultados en el desarrollo de servicios, Real Patronato sobre Discapacidad, Madrid, 2003.

[9] J. Kregel and P. Wehman, Supported Employment research: impacting the work outcomes of individuals with disabilities, RRTC Summer, 1996.

[10] D. Mank, El proyecto de investigación de apoyos naturales se consolida, in: II Jornadas Científicas de Investigación sobre Personas con Discapacidad. Libro de Actas, M.A. Verdugo, C. Caballo, F.B. Jordán de Urríes, M. Crespo, C. Jenaro, M.I. Tena, F. Sainz and y E. Díez, comp., Instituto de Integración en la Comunidad, Salamanca, 1997, pp. 63-74.

[11] D. Mank, A. Cioffi and P. Yovanoff, Analysis of the typicalness of Supported Employment jobs, natural supports, and wage 
and integration outcomes, Mental Retardation 35(3) (1997a), 185-197.

[12] D. Mank, A. Cioffi and P. Yovanoff, Patterns of support for employees with severe disabilities, Mental Retardation 35(6) (1997b), 433-447.

[13] D. Mank, A. Cioffi and P. Yovanoff, Employment outcomes for people with more severe disabilities, Mental Retardation 36(3) (1998), 205-216.

[14] R. Pirttimaa and T. Saloviita, Supported employment in Finland six years following its introduction, Journal of Vocational Rehabilitation 17 (2002), 301-307.

[15] J. Ridley and S. Hunter, Infusion Co-operative, Go for It! Supporting People with Learning Disabilities and/or ASD in Employment, Scottish Executive, Edinburgh, 2005.

[16] T. Saloviita and R. Pirttimaa, The arrival of Supported Employment in Finland, International Journal of Rehabilitation Research 23 (2000), 145-147.

[17] T. Saloviita and R. Pirttimaa, Supported Employment Survey in Finland, Journal of Policy and Practice in Intellectual Disabilities 4(4) (2007), 229-234.

[18] Ø. Spjelkavik and M.J. Evans, Impression of Supported Employment, A study of some European Supported Employment services and their activities, Work Research Institute, Oslo, 2007.

[19] P. Thornton, P. Banks, S. Riddell and S. Beyer, A Study of Providers New to WORKSTEP, Research Report W195,
Department of Work and Pensions Research Management, Sheffield, 2004

[20] M.A. Verdugo, F.B. Jordán de Urríes, F. Bellver and S. y Martínez, Supported Employment in Spain, Journal of Vocational Rehabilitation 11 (1998), 223-232.

[21] M.A. Verdugo, F.B. Jordán de Urríes and F. Bellver, Situación actual del empleo con apoyo en España, Siglo Cero 29(1) (1998), 23-31.

[22] M.A. Verdugo, R. Martín-Ingelmo, F.B. Jordán de Urríes, C. Vicent and M.C. Sánchez, Impact of quality of life and selfdetermination of a national program for increasing Supported Employment in Europe, Journal of Vocational Rehabilitation 31(1) (2009), 55-64.

[23] M.A. Verdugo and F.B. Jordán de Urríes, Panorámica del empleo con apoyo en España, Real Patronato sobre Discapacidad, Madrid, 2001.

[24] P. Wehman, Achievements and challenges: a five-year report on the status of the national Supported Employment initiative, FY 1986-1990, Virginian Commonwealth University, Rehabilitation Research and Training Center, Richmond, 1992.

[25] M. West, G. Revell and P. Wehman, Achievements and challenges I: A five year report on consumer and system outcomes from the Supported Employment initiative, Journal of the Association for Persons With Severe Handicaps 17(24) (1992), 227-235. 